\title{
Pathways of care of women in secure hospitals: which women go where and why
}

\author{
Annie Bartlett, Nadia Somers, Matthew Fiander and Mari Anne Harty
}

\section{Background}

Care pathways for women needing expensive, secure hospital care are poorly understood.

\section{Aims \\ To characterise women in low and medium security hospitals in England and Wales and to compare populations by security and service provider type.}

\section{Method}

Census data from all specialist commissioning areas. Sociodemographic, clinical, medico-legal, criminological and placement needs data were requested on all women in low and medium secure hospital beds. Parametric tests were used for continuous data and chi-square or Fisher's exact tests for categorical data. Thematic analysis was used for free text data.

\section{Results}

The independent sector is the main service provider. A third of all women $(n=1149)$ were placed outside their home region despite spare local National Health Service (NHS) capacity. The independent sector provides for women with relatively rare disorders, including intellectual disability. The NHS admits most serious offenders. One in 20 are detained because of self-harm alone.

\section{Conclusions}

Patient-specific factors (notably the diagnosis of personality disorder) and organisational inadequacy (commissioner and service provider) contribute to placements that compromise rehabilitation. Responses should include local solutions for women whose main risk is self-harm and a national approach to women with highly specialist needs.

\section{Declaration of interest}

A.B., M.F. and N.S. report salary support from London NHS Mental Health Specialist Commissioning Group during the conduct of the study; M.A.H. works in an NHS medium secure unit.
The development of women's secure psychiatric services in England and Wales has been influenced by both UK government policy $^{1}$ and competition among health providers. ${ }^{2}$ No national picture of placements or pathways has been available. The high cost of these services, ${ }^{3}$ changes in commissioning structures (Health and Social Care Act 2012), the development of a national women's secure services strategy ${ }^{4}$ and the intended development of a national service specification for women's services makes it essential to understand large-scale service usage. This study describes and analyses current patterns of care, delineating differences between National Health Service (NHS) and independent sector providers and raises questions about the impact on clinical care of real life decision-making in a complex health system. High, medium and low secure hospital care is a small but significant component of all psychiatric hospital bed provision in England and Wales. Security criteria are specified for high and medium secure care and are in development for low secure care. ${ }^{5,6}$ Both the independent sector (for-profit and not-for-profit health organisations) and the NHS (state provision) provide secure and non-secure psychiatric beds.

\section{Method}

Demographic, clinical and placement data are reported here on women in low and medium secure care based on comprehensive census data in England and Wales. An analysis of these data are presented by type of healthcare provider and by level of security; specifically the extent to which independent sector and NHS populations are the same or different and whether the distinction in tiers of security is or is not reflected by variation in patient characteristics.

Data collection on women detained in low and medium secure beds involved the completion of questionnaires on a census date
(7 September 2011 at $06.00 \mathrm{~h}$ ) by service managers and consultant forensic psychiatrists in units identified earlier (see Harty et $a l^{7}$ ). The questionnaires used were discussed and piloted with a group of colleagues at the London Women's Services Forum. Nine of the ten specialised commissioning groups in England and the Welsh Health Specialised Services Committee took part in the study. One commissioning group declined but the NHS secure units in this region agreed to take part. The sample size was determined by the number of beds occupied on the census date.

\section{Measures}

The study questionnaire requested demographic (age, ethnicity), clinical (primary and secondary diagnosis) and placement needs data. Index offence or offending behaviour, medico-legal status, current security level and source of admission were also obtained. Offence data were available both on those women detained under Part III criminal section of the Mental Health Act 1983 (MHA) (revised 2007), Criminal Procedure Insanity and Unfitness to Plead Act and on those detained under Part II civil sections as well as the small number who were informal patients. These data are different in terms of whether or not they have been considered in the criminal courts but are clinically relevant to detention in different levels of security. Placement need questions reported here related to time frames for progression and anticipated destinations.

Service evaluation status was confirmed by the National Research Ethics Service and South West and St George's Mental Health NHS Trust. Research and development approval was granted by South West and St George's Mental Health NHS Trust. Approval was also granted by each participating NHS trust and independent sector provider. 


\section{Data resolution and data analysis}

Data resolution

Labelling issues regarding the security level of provider units emerged as data were collected. There were three units with 'hybrid' beds. 'Hybrid' beds can change in their security status. The highest level of security to which patients could be admitted determined the reported level of security. The sample does not include non-secure rehabilitation, open or stepdown facilities. In two mixed units where there was no fixed number of female beds (i.e. beds could be allocated to either men or women, depending on need), the actual number of women in beds on the census date was used to establish occupancy.

Data analysis

Quantitative data analysis was conducted using SPSS Version 19 for Windows. Data were examined with the aim of illuminating aspects of pathways of care i.e. how women had come to be in their current placements, whether there was a pattern to the placement of women with particular difficulties, the extent to which they were close to home, etc. 'Home region' was defined as the primary care trust or local authority and the associated secure commissioning group region that holds responsibility for the patient. 'Away from home region/out of area placement' was defined as women who are the responsibility of a region but placed in a unit outside of that region.

Parametric tests were used for continuous data. Chi-square or Fisher's exact tests were used for categorical data. As length of stay data were highly skewed, a poisson regression approach was used to test for differences in stay lengths between groups. Thematic analysis of reasons for detention in the absence of offending behaviour was carried out. Two experienced qualitative researchers (A.B. and M.F.) agreed a descriptive coding framework, A.B. applied it and M.F. reviewed it.

\section{Results}

It has been established that there are currently 1625 low, medium or enhanced medium secure beds for women (Women's Enhanced Medium Secure Services, WEMSS) in England and Wales, of which $17 \%$ are in learning disability units. ${ }^{5}$ On the study census date there were 1314 women in these beds with an overall occupancy rate of $81 \%$. Data reported here are on 1149 (90\%) of the 1273 women ( 41 women in WEMMS will not be considered here), based on the response rate. Questionnaires were not returned from five independent sector units (65 occupied beds) and three NHS units (28 occupied beds) from three different geographical health regions. None of these units were described as learning disability units. All eight units informed the study of their bed and occupancy numbers on the census date. The remaining 31 missing questionnaires were from units scattered across the country that had otherwise fully participated in the study. The overall response rate was slightly higher from the NHS than the independent sector units (NHS 92\%; independent sector $90 \%$ ).

The total occupancy (independent sector and NHS) for low secure beds was 773 women and for medium secure beds was 500 women. Data are available on $672(87 \%)$ women in low secure beds and 477 (95\%) in medium secure beds (total 1149 women). Occupancy figures showed that the independent sector had twice as many women detained in low secure beds whereas the NHS had a third more in medium secure beds. Further, NHS medium and low secure beds were more likely to be occupied than independent sector beds. Bed occupancy according to level of security and sector of provider (NHS and independent sector) is shown in Table 1.

\section{Key characteristics of women in low and medium secure care $(n=1149)$}

The median age of all women in our sample in medium and low secure units was 33.8 years. Most women were White $(n=951$, $84.7 \%$ ). The most common primary diagnoses were of psychotic disorders $(n=491,43 \%)$ and personality disorder $(n=434$, $38 \%)$. However, $9 \%(n=100)$ of patients had a primary diagnosis of intellectual disability (referred to as learning disability by UK health services: significant impairment in intellectual and adaptive and social functioning established using standardised diagnostic tools). Over half $(n=603,53 \%)$ of all women had a secondary diagnosis, most commonly emotionally unstable personality disorder $(n=147,13 \%)$ followed by substance misuse $(n=106,9 \%)$. Seventy women $(6 \%)$ had a secondary diagnosis of intellectual disability and a further $43(4 \%)$ had dis-social personality disorder; 14 (1\%) had a secondary diagnosis of an autistic spectrum disorder. Sixty-three other women (6\%) had more than two diagnoses.

Exploration of the legal basis for detention revealed that half $(n=550,49 \%)$ of all women were detained under the civil part (Part II) of the MHA (Sections 2, 3 or 5:2) with a handful being held informally $(n=6)$. The rest were detained under criminal sections (Part III of the MHA) with 316 (28\%) subject to Section 37 with the additional Section 41 (imposed by Crown Courts indicating risk of serious harm). Sixty-nine patients $(6 \%)$ were transferred prisoners.

\section{Clear differences between the low and medium secure populations}

Comparison of the characteristics of women detained in low as opposed to medium secure beds was undertaken to see if the populations were distinct and to see if risk-related variables were associated with higher security. Significant differences between low and medium secure populations included their ethnicity,

\begin{tabular}{|c|c|c|c|c|c|c|}
\hline & \multicolumn{2}{|c|}{ Low security } & \multicolumn{2}{|c|}{ Medium security } & \multirow{2}{*}{$\begin{array}{l}\text { Enhanced medium security } \\
\text { NHS }\end{array}$} & \multirow[b]{2}{*}{ Totals } \\
\hline & Independent sector & NHS & Independent sector & NHS & & \\
\hline Beds, $n^{\mathrm{a}}$ & 745 & 245 & 280 & 309 & 46 & 1625 \\
\hline \multicolumn{7}{|l|}{ Bed occupancy } \\
\hline$n$ & 547 & 226 & 218 & 282 & 41 & 1314 \\
\hline$\%$ of all beds & 73 & 92 & 78 & 91 & 89 & 81 \\
\hline \multicolumn{7}{|l|}{ Returned surveys } \\
\hline$n$ & 476 & 196 & 210 & 267 & 41 & 1190 \\
\hline$\%$ of occupied beds & 87 & 87 & 96 & 95 & 100 & 91 \\
\hline
\end{tabular}


source of admission, the likelihood of being placed in a unit in their health region of origin, the pattern of primary diagnoses, the offences leading to admission and type of MHA section used for compulsory detention. No significant differences were detected in terms of women's age or length of stay. The medium secure population included a higher proportion of women from Caribbean or African backgrounds than did the low secure population $\left(\chi^{2}=12.680, P=0.027, P<0.05\right)$.

The pattern of admissions to medium and low secure units differed (Table 2). Prison was the most likely source of admission to medium secure beds $(n=169,36 \%)$ whereas general psychiatric beds were the most likely source of admission to low secure beds $(n=123,20 \%)$. High rates of transfer between beds of the same level of security (level transfers) were noted, amounting to a third $(n=157,33 \%)$ of all admissions to medium security and over a quarter of all admissions to low security $(n=172,27 \%)$.

Women in low secure facilities were more likely to be resident outside their region of origin $(n=263,39 \%)$ than women in medium secure facilities $(n=153,32 \%)$ (Pearson's $\chi^{2}=6.276$, $P=0.012$ ). Examination of women's primary diagnosis (collapsed categories) in low security found significant differences (Pearson's $\left.\chi^{2}=33.325, P<0.001\right)$ in the pattern of disorders in low and medium security. Importantly, three out of five women (59.7\%) with intellectual disability were in low secure beds.

Women in low secure units were twice as likely to be detained under civil sections or informally $(n=412,63 \%)$ compared with those detained in medium security $(n=144,31 \%)$ (Pearson's $\left.\chi^{2}=110.314, P<0.001\right)$. Further, women in medium secure units ( $n=186,40 \%$ ) were twice as likely to be subject to Section $37 / 41$ compared with those in low security $(n=130,20 \%)$. Prison transfers were more common in the medium secure population ( $n=43,9 \%)$ compared with the low secure population $(n=26,4 \%)$.
Most women detained in relation to a homicide $(n=46,4.2 \%)$ were in medium secure care and they constituted a greater proportion $(n=37,8 \%)$ of the medium secure population ( $n=464,100 \%)$ than did the small number of such women $(n=9,1.4 \%)$ in low secure care $(n=624,100 \%)$. Only four of these women were held on civil sections of the MHA or were informal. Forty-two were on criminal sections of the MHA. Other serious offences such as attempted murder, kidnap and grievous bodily harm were also more common in the medium secure population $(n=71$ patients, $15.3 \%)$ than in low security $n=52$ patients, $8.3 \%)$.

An important discovery was that, according to the responsible clinicians, in a quarter of all cases $(n=276,223$ in low secure units and 53 in medium security) no offence (whether or not prosecuted) relevant to detention was identified. In all these cases the women were detained on civil sections $(n=254)$ or were informal $(n=3)$ (MHA section data were missing for $n=19$ women). Exploration of the responses for the 257 women who were on civil sections or informal revealed that in nine cases no additional information was provided by clinicians. In the remaining 248 cases, additional information was provided (Table 4). In 69 cases the only behaviour mentioned was risk to self, selfharm or suicide although in a further 42 cases, some kind of risk to self was a component of the behaviour identified by the clinicians.

\section{Evident differences between populations in the NHS and independent sector}

An initial comparison was made between women in the independent sector and those in the NHS. Several differences were evident. Those in the independent sector were younger (median

Table 2 Source of admission to women's low and medium secure beds $(n=1098)^{\mathrm{a}}$

\begin{tabular}{|c|c|c|c|c|c|c|}
\hline & \multicolumn{2}{|c|}{ Low } & \multicolumn{2}{|c|}{ Medium } & \multicolumn{2}{|c|}{ Total } \\
\hline & $n$ & $\%$ & $n$ & $\%$ & $n$ & $\%$ \\
\hline Community & 34 & 5 & 21 & 4 & 55 & 5 \\
\hline Prison & 88 & 14 & 169 & 36 & 257 & 23 \\
\hline General psychiatric bed & 123 & 20 & 27 & 6 & 150 & 14 \\
\hline Psychiatric intensive care unit & 86 & 14 & 19 & 4 & 105 & 10 \\
\hline Low secure & 172 & 27 & 49 & 10 & 221 & 20 \\
\hline Medium secure & 104 & 17 & 157 & 33 & 261 & 24 \\
\hline High secure & 5 & 1 & 21 & 4 & 26 & 2 \\
\hline Other & 11 & 2 & 6 & 1 & 16 & 1 \\
\hline Enhanced medium secure beds for women & 5 & 1 & 2 & 0 & 7 & 1 \\
\hline Total & 628 & 100 & 471 & 100 & 1099 & 100 \\
\hline
\end{tabular}

Table 3 Primary diagnoses of women in low and medium secure beds $(n=1138)^{a, d}$

\begin{tabular}{|c|c|c|c|c|c|c|}
\hline & \multicolumn{2}{|c|}{ Low } & \multicolumn{2}{|c|}{ Medium } & \multicolumn{2}{|c|}{ Total } \\
\hline & $n$ & $\%$ & $n$ & $\%$ & $n$ & $\%$ \\
\hline Psychotic disorders ${ }^{\mathrm{b}}$ & 263 & 39.5 & 229 & 48.5 & 492 & 43.2 \\
\hline Affective disorders ${ }^{c}$ & 26 & 3.9 & 23 & 4.9 & 49 & 4.3 \\
\hline Other & 34 & 5.1 & 29 & 6.1 & 63 & 5.5 \\
\hline Personality disorders & 259 & 38.9 & 175 & 37.1 & 434 & 38.1 \\
\hline Intellectual disability & 84 & 12.6 & 16 & 3.4 & 100 & 8.8 \\
\hline Total & 666 & 100.0 & 472 & 100.0 & 1138 & 100.0 \\
\hline \multicolumn{7}{|c|}{$\begin{array}{l}\text { a. Eleven individuals with diagnosis data missing are excluded. Percentages may not add up to } 100 \text { because of rounding. } \\
\text { b. Psychotic disorders include schizophrenia and schizoaffective disorder. } \\
\text { c. Affective disorders include bipolar affective disorder and depressive disorders. } \\
\text { d. Pearson's } \chi^{2}=33.325, P<0.001 \text {. }\end{array}$} \\
\hline
\end{tabular}


age 31.6 years) than women in the NHS (median age 36.8 years) $(t=4.51, P<0.001)$. Ethnicity varied significantly by type of provider (NHS and independent sector) $\left(\chi^{2}=27.905, P<0.001\right)$. Women in NHS facilities were more likely to come from a Black and minority ethnic background.

More women in the NHS $(n=105)$ than the independent sector $(n=64)$ had offences of homicide, attempted murder, kidnap or grievous bodily harm (GBH). By contrast, there were three times as many women in the independent sector whose responsible clinician did not identify any offence associated with admission to hospital $(n=206)$ than the NHS $(n=70)$.

Examination of length of stay up to the census date revealed an average of 751 days (s.d.=801.76). This was significantly shorter for women in independent sector units, where mean length of stay was 698 days (95\% CI 642.1-753.0) than those in NHS units, where mean length of stay was 830 days (95\% CI 749.6-910.8, Wald $\left.\chi^{2}=7.3, P=0.007\right)$. The difference in length of stay between NHS and independent sector units was not affected by level of security (Wald $\chi^{2}=1.5, P=0.224$ ).

Thirty-six $(n=416)$ per cent of all women were placed in a unit outside of their home region (Table 5). Most women in independent sector beds were placed outside their home region. This contrasted with very few women in NHS beds (Pearson's $\left.\chi^{2}=365.803, P<0.001\right)$.

Differences in the distribution of legal detention were noted between NHS and independent sector providers. The majority of patients detained under civil sections were in the independent sector (NHS: $n=171 ; 38 \%$, independent sector: $n=379,57 \%$ ). By contrast, the NHS detained a larger number of women who were subject to Section 37/41 than the independent sector; proportionately, this was almost twice that of independent sector units (NHS: $n=170,38 \%$; independent sector: $n=146,22 \%$ ). These differences reached statistical significance (Pearson's $\left.\chi^{2}=47.690, P<0.001\right)$.

It is clear that the total NHS and independent sector populations varied in terms of a range of key characteristics.
Although this is helpful in describing the overall pattern of care, the analysis is inconclusive as the populations are of different sizes. Notably, the independent sector provides a much larger number of low secure beds. An additional set of comparisons between NHS and independent sector low secure populations (Table 6) and then separately NHS and independent sector medium secure populations (Table 7) was undertaken. This was to see if these two groups of providers were being used in the same way for women requiring care at those particular levels of security. Several significant differences in the populations emerged from this approach.

\section{Independent sector and NHS low secure female populations} are different

Key differences confirmed between the NHS and independent sector low secure populations were the age of the women (NHS women were older), their ethnic group (Fisher's exact test 14.279, $P<0.001$ ), source of admission (Fisher's exact test 61.618, $P<0.001)$, likelihood of home region placement, primary diagnosis (Pearson's $\chi^{2}=35.207, P<0.001$ ) and offence profile (Pearson's $\left.\chi^{2}=20.701, P<0.023\right)$. There were no significant differences in length of stay or use of civil or criminal MHA sections for detention.

The independent sector provides the majority of low secure beds. The way in which they are used results in large numbers of women being admitted to low secure beds outside their home region. Women in NHS low secure beds were almost always resident within their region of origin. This difference is statistically significant (Pearson's $\chi^{2}=146.491, P<0.001$ ). Only seven women $(3.6 \%)$ in the NHS low secure population $(n=194,100 \%)$ are placed out of home region compared with 256 (54\%) in the independent sector $(n=474,100 \%)$.

Significant differences in the distribution of patients' primary diagnosis by low secure provider (NHS and independent sector) are evident in Table 6. Most of the women with psychotic disorders $(n=263,100 \%)$ were in the independent sector $(n=170,64.6 \%)$ and most of the women with personality

Table 4 Reason for detention in the absence of an index offence or offending behaviour $(n=257)^{\text {a }}$

\begin{tabular}{|c|c|c|c|c|c|c|}
\hline & \multicolumn{2}{|c|}{ Low } & \multicolumn{2}{|c|}{ Medium } & \multicolumn{2}{|c|}{ Total } \\
\hline & $n$ & $\%$ & $n$ & $\%$ & $n$ & $\%$ \\
\hline Self-harm only & 61 & 28.9 & 8 & 17.4 & 69 & 26.8 \\
\hline Self-harm and actual or threatened harm to others & 26 & 12.3 & 16 & 34.8 & 42 & 16.3 \\
\hline No explanation & 9 & 4.3 & 0 & 0 & 9 & 3.5 \\
\hline $\begin{array}{l}\text { Quasi or actual diagnostic term without } \\
\text { additional information }\end{array}$ & 33 & 15.6 & 5 & 10.9 & 38 & 14.8 \\
\hline $\begin{array}{l}\text { Aggression or harm to others (threat/actual) without harm to self } \\
\text { but may include vulnerability }\end{array}$ & 27 & 12.8 & 11 & 23.9 & 38 & 14.8 \\
\hline Quasi or actual diagnostic term without additional information & 11 & 5.2 & 1 & 2.2 & 12 & 4.7 \\
\hline 'Challenging behaviour' alone or plus something else & 14 & 6.6 & 1 & 2.2 & 15 & 5.8 \\
\hline Other & 30 & 14.2 & 4 & 8.7 & 34 & 13.2 \\
\hline Total & 211 & 100.0 & 46 & 100.0 & 257 & 100.0 \\
\hline
\end{tabular}

Table 5 Location of women in National Health Service and independent sector secure beds $(n=1144)^{\mathrm{a}, \mathrm{b}}$

\begin{tabular}{|c|c|c|c|c|c|c|}
\hline & \multicolumn{2}{|c|}{ Home region } & \multicolumn{2}{|c|}{ Elsewhere } & \multicolumn{2}{|c|}{ All } \\
\hline & $n$ & $\%$ & $n$ & $\%$ & $n$ & $\%$ \\
\hline Independent sector & 282 & 39 & 401 & 96 & 683 & 60 \\
\hline National Health Service & 446 & 61 & 15 & 4 & 461 & 40 \\
\hline Total & 728 & 100 & 416 & 100 & 1144 & 100 \\
\hline
\end{tabular}


Table 6 Sociodemographic and forensic features of women in low secure beds ${ }^{a}$

\begin{tabular}{|c|c|c|c|c|c|c|c|}
\hline & Independent sector & NHS & Total & $t$ & $\chi^{2}$ & $P$ & $\begin{array}{l}\text { Mean difference } \\
\qquad(95 \% \mathrm{Cl})\end{array}$ \\
\hline Age, years $(n=672)$ & & & & 2.07 & & 0.039 & $1.97(0.1-3.83)$ \\
\hline Mean (s.d.) & $34.90(11.15)$ & $36.87(11.31)$ & $35.47(11.23)$ & & & & \\
\hline Median (minimum/maximum) & $32.56(18.37 / 66.35)$ & $37.61(18.71 / 64.49)$ & $33.86(18.37 / 66.35)$ & & & & \\
\hline Length of stay, days ( $n=665$ ) & & & & & $1.95^{\mathrm{b}}$ & 0.162 & \\
\hline Mean (s.d.) & $735.46(764.44)$ & 838.97 (944.57) & 765.19 (820.84) & & & & \\
\hline Median (minimum/maximum) & $484.5(6 / 4144)$ & $531.0(2 / 5908)$ & $504.0(2 / 5908)$ & & & & \\
\hline Primary diagnosis $(n=666), n(\%)$ & & & & & 35.207 & $<0.001$ & \\
\hline Psychotic disorders & $170(35.7)$ & $93(48.9)$ & $263(39.5)$ & & & & \\
\hline Personality disorders & $210(44.1)$ & $49(25.8)$ & 259 (38.9) & & & & \\
\hline Affective disorders & $26(5.5)$ & $8(4.2)$ & $34(5.1)$ & & & & \\
\hline Intellectual disability & $46(9.7)$ & $38(20)$ & $84(12.6)$ & & & & \\
\hline Other & $24(5.0)$ & $2(1.1)$ & $26(3.9)$ & & & & \\
\hline Total & $476(100)$ & $190(100)$ & $666(100)$ & & & & \\
\hline Mental Health Act Section $(n=648)$ & & & & & 1.174 & 0.279 & \\
\hline Civil or informal & $299(64.3)$ & $113(59.8)$ & $412(63.0)$ & & & & \\
\hline Criminal (including CPIA) & $166(35.7)$ & $76(40.2)$ & $242(37.0)$ & & & & \\
\hline Total & $465(100.0)$ & $189(100.0)$ & $654(100.0)$ & & & & \\
\hline Index offence $(n=604)$ & & & & & 20.701 & 0.023 & \\
\hline Homicide & 7 (1.6) & $2(1.1)$ & $9(1.4)$ & & & & \\
\hline Attempted murder, kidnap, GBH & $32(7.2)$ & $20(11.2)$ & $52(8.3)$ & & & & \\
\hline $\mathrm{ABH}$, threats, weapons & $107(24.0)$ & $61(34.1)$ & $168(26.9)$ & & & & \\
\hline Rape, indecent assault & $2(0.4)$ & $3(1.7)$ & $5(0.8)$ & & & & \\
\hline Robbery, firearms offences & $3(0.7)$ & $3(1.7)$ & $6(1.0)$ & & & & \\
\hline Arson & $73(16.4)$ & $21(11.7)$ & $94(15.1)$ & & & & \\
\hline Criminal damage & $9(2.0)$ & 7 (3.9) & $16(2.6)$ & & & & \\
\hline Theft, burglary, forgery & $7(1.6)$ & $2(1.1)$ & $9(1.4)$ & & & & \\
\hline Drug and alcohol related & $8(1.8)$ & $4(2.2)$ & $12(1.9)$ & & & & \\
\hline Other offence & $22(4.9)$ & $8(4.5)$ & $30(4.8)$ & & & & \\
\hline None & 175 (39.3) & $48(26.8)$ & $223(35.7)$ & & & & \\
\hline Total & 445 (100.0) & 179 (100.0) & $624(100.0)$ & & & & \\
\hline
\end{tabular}

disorders $(n=259,100 \%)$ were in the independent sector $(n=210$, $81.1 \%)$. However, the NHS is still most likely to care for those with psychotic disorders, who form a larger component of their total population. The independent sector low secure providers cared for 13 of 14 women with autistic spectrum disorders.

Comparison of the use of civil MHA sections (or informal admission) or criminal MHA sections in low secure provision shows no significant difference between the independent sector and NHS. However, four out of five women who, in the opinion of their responsible clinician, were not in hospital in relation to offending behaviour were cared for in the independent sector.

Independent sector and NHS medium secure female populations are different

Similar analysis of medium secure populations in the NHS and independent sector revealed an even greater range of differences than in the low secure providers' populations. Women in these facilities differed in terms of age, ethnicity (Fisher's exact test $33.137, P<0.001$ ), source of admission, admission to hospital in their own region (Pearson's $\chi^{2}=236.847, P<0.001$ ), primary diagnoses, use of civil or criminal MHA sections for detention, offence profile and length of stay.

Women in medium secure beds in the NHS were on average 5 years older than those in independent sector medium secure beds, (95\% CI 3.16-6.93 years); they were also more likely to come from a non-White background, mainly African or Caribbean (Fisher's Exact test 33.137, $P<0.001$ ). The NHS was more likely to admit from the community and the independent sector more likely to admit from low secure beds (Fisher's exact test 22.136,
$P<0.001)$. Only eight women $(3.0 \%)$ of the 267 in NHS medium secure beds were located out of their home region. Of the women in independent sector beds $(n=209)$, twice as many were out of their region $(n=145)$ as in it $(n=64)$ (Pearson $\chi^{2}=236.847$, $P<0.001)$. The NHS cares mainly for women with major mental illness and has three times as many women with a primary diagnosis of paranoid schizophrenia as the independent sector. The independent sector focuses more on women with personality disorder, particularly emotionally unstable personality disorder. The NHS takes women with a higher offending profile, notably homicide, attempted murder, kidnap and GBH. This is reflected in the higher use of criminal sections of the MHA.

\section{Where women should be now and in the future}

Our analysis has considered how women came to be placed in their current units. This is one aspect of the care pathway. Equally important is the likely next step. We have so far described four overlapping but also substantially different populations according to both level of security and type of provider. We now report likely future placement needs, based on the responsible clinicians' views on the low (Table 8) and medium (Table 9) secure populations but incorporating potential differences by type of provider. Overall, $93 \%$ of patients were considered by their responsible clinicians to be placed in the right level of security on the census date. This was true for both low and medium security (Tables 8 and 9) and there were only small differences evident between the independent sector and NHS responsible clinicians' opinions.

More detailed scrutiny of the individual tiers of security showed a difference in recommended placement in 1 year and 


\begin{tabular}{|c|c|c|c|c|c|c|c|}
\hline & Independent sector & NHS & Total & $t$ & $\chi^{2}$ & $P$ & $\begin{array}{c}\text { Mean difference } \\
(95 \% \mathrm{Cl})\end{array}$ \\
\hline Age, years $(n=672)$ & & & & 5.26 & & $<0.001$ & $5.05(3.16-6.93)$ \\
\hline Mean (s.d.) & $32.04(9.98)$ & $37.09(10.66)$ & $34.87(10.66)$ & & & & \\
\hline Median (minimum/maximum) & $30.28(18.17 / 57.42)$ & $36.26(18.77 / 76.10)$ & $33.71(18.17 / 76.10)$ & & & & \\
\hline Length of stay, days $(n=665)$ & & & & & $9.06^{b}$ & 0.003 & \\
\hline Mean (s.d.) & $611.77(682.44)$ & 823.84 (829.34) & 730.39 (774.50) & & & & \\
\hline Median (minimum/maximum) & $373.5(2 / 4321)$ & $637.5(1 / 5951)$ & $513.5(1 / 5951)$ & & & & \\
\hline Primary diagnosis $(n=666), n(\%)$ & & & & & 46.227 & $<0.001$ & \\
\hline Psychotic disorders & $68(32.5)$ & $161(61.2)$ & $229(48.5)$ & & & & \\
\hline Personality disorders & $100(47.8)$ & $75(28.5)$ & $175(37.1)$ & & & & \\
\hline Affective disorders & $12(5.7)$ & $17(6.5)$ & $29(6.1)$ & & & & \\
\hline Intellectual disability & $11(5.3)$ & $5(1.9)$ & $16(3.4)$ & & & & \\
\hline Other & $18(8.6)$ & $5(1.9)$ & $23(4.9)$ & & & & \\
\hline Total & $209(100.0)$ & $263(100.0)$ & $472(100.0)$ & & & & \\
\hline Mental Health Act Section $(n=648)$ & & & & & 16.153 & $<0.001$ & \\
\hline Civil or informal & $83(40.9)$ & $61(23.5)$ & $144(31.1)$ & & & & \\
\hline Criminal (including CPIA) & $120(59.1)$ & $199(76.5)$ & $319(68.9)$ & & & & \\
\hline Total & $203(100.0)$ & $260(100.0)$ & $463(100.0)$ & & & & \\
\hline Index offence $(n=604)$ & & & & & 45.803 & $<0.001$ & \\
\hline Homicide & $8(4.0)$ & $29(11.0)$ & $37(8.0)$ & & & & \\
\hline Attempted murder, kidnap, GBH & $17(8.5)$ & $54(20.5)$ & $71(15.3)$ & & & & \\
\hline $\mathrm{ABH}$, threats, weapons & $83(41.5)$ & $66(25.0)$ & $149(32.1)$ & & & & \\
\hline Rape, indecent assault & $7(3.5)$ & $3(1.1)$ & $10(2.2)$ & & & & \\
\hline Robbery, firearms offences & $6(3.0)$ & $8(3.0)$ & $14(3.0)$ & & & & \\
\hline Arson & $36(18.0)$ & $66(25.0)$ & $102(22.0)$ & & & & \\
\hline Criminal damage & $1(0.5)$ & $5(1.9)$ & $6(1.3)$ & & & & \\
\hline Theft, burglary, forgery & $6(3.0)$ & $1(0.4)$ & $7(1.5)$ & & & & \\
\hline Drug and alcohol related & $0(0.0)$ & $1(0.4)$ & $1(0.2)$ & & & & \\
\hline Other offence & $5(2.5)$ & $9(3.4)$ & $14(3.0)$ & & & & \\
\hline None & $31(15.5)$ & $22(8.3)$ & $53(11.4)$ & & & & \\
\hline Total & $200(100.0)$ & $264(100.0)$ & $464(100.0)$ & & & & \\
\hline
\end{tabular}

4 years, depending on whether the woman was in the independent sector or NHS. Strikingly, the NHS low secure responsible clinicians thought half of the women they cared for should be in the community in a year's time, whereas the independent sector low secure responsible clinicians were more likely to consider that there should be no change in security level. This pattern remained true in relation to where the women should be in 4 years. The women in the NHS low secure beds would almost all be discharged from hospital compared with only four in five of the independent sector women.

Similarly, NHS medium secure responsible clinicians thought a quarter of the women they cared for could be discharged in 1 year. The independent sector responsible clinicians thought fewer than 1 in 10 could. This difference was retained at 4 years so that three-quarters of women in the NHS medium secure beds were thought likely to be suitable for discharge and only six out of ten in the independent sector. In both low and medium secure settings, return to prison settings was seldom thought appropriate.

\section{Discussion}

This is the first time a level of contemporaneous transparency has been achieved in relation to the English and Welsh populations of women in secure hospital care. In summary, these findings characterise the women in low and medium secure units and demonstrate convincingly that there are, in effect, four overlapping but distinct populations. This study also provides pathway data that suggest these populations have different patterns of entry and likely exit from their current placements. In the case of the medium and low secure populations this is reassuring. Different tiers of secure care were designed to care for women posing different levels of risk. The analysis by type of provider reveals how several issues have arisen inadvertently. Some women appear detained in secure settings without easy evidence of risk to others. Many women are located out of their home region. The independent sector is the main provider of these services, it is thought by its own analysis to be more expensive ${ }^{8}$ and yet the NHS services are not fully occupied. There is a need to consider carefully how and why this pattern of care has arisen, the extent to which it is appropriate and whether there is scope for improvement in the light of a national data-set.

\section{Placement and risk}

The principle of the secure units is that that a higher level of security should reflect a population of apparently greater risk to others than would be the case in a unit of lower security. This study reports crude and robust, rather than subtle, markers of apparent risk, but these have often been tested in criminal courts or Ministry of Justice assessments (for prison transfers). That fewer women are admitted to secure care without criminal convictions than men ${ }^{9,10}$ is known but the very high figures for low security have not been previously documented. The absence of a criminal conviction does not mean that women have not engaged in dangerous behaviours; clinicians are required to make judgements about the level of seriousness of individuals' actions, even in the absence of criminal convictions. More debatable is that more than 1 in 20 women in secure care are apparently there because of the risk to themselves, not to others. The fact that such women are predominantly resident in the independent sector is 
Table 8 Women's placement needs by sector for those in low secure beds

\begin{tabular}{|c|c|c|c|c|c|c|c|c|c|}
\hline & \multicolumn{2}{|c|}{ Independent sector } & \multicolumn{2}{|c|}{ NHS } & \multicolumn{2}{|c|}{ Total } & \multirow{2}{*}{$\begin{array}{l}\text { Fisher's } \\
\text { exact test }\end{array}$} & \multirow[b]{2}{*}{$\chi^{2}$} & \multirow[b]{2}{*}{$P$} \\
\hline & $n$ & $\%$ & $n$ & $\%$ & $n$ & $\%$ & & & \\
\hline $\begin{array}{l}\text { Responsible clinician considers patient to be at the } \\
\text { right level of security on census date }\end{array}$ & & & & & & & & 1.519 & 0.218 \\
\hline Yes & 441 & 93.8 & 175 & 91.1 & 616 & 93.1 & & & \\
\hline No & 29 & 6.2 & 17 & 8.9 & 46 & 6.9 & & & \\
\hline Total & 470 & 100.0 & 192 & 100.0 & 662 & 100.0 & & & \\
\hline Recommended placement in 1 year & & & & & & & 16.045 & & $<0.001$ \\
\hline Community & 156 & 35.6 & 92 & 51.4 & 248 & 40.2 & & & \\
\hline In-patient & 123 & 28.1 & 44 & 24.6 & 167 & 27.1 & & & \\
\hline Low secure unit & 147 & 33.6 & 41 & 22.9 & 188 & 30.5 & & & \\
\hline Medium secure unit & 5 & 1.1 & 2 & 1.1 & 7 & 1.1 & & & \\
\hline Other secure environment & 7 & 1.6 & 0 & 0 & 7 & 1.1 & & & \\
\hline Total & 438 & 100.0 & 179 & 100.0 & 617 & 100.0 & & & \\
\hline Recommended placement in 4 years & & & & & & & 24.971 & & $<0.001$ \\
\hline Community & 347 & 80 & 168 & 92.3 & 515 & 83.6 & & & \\
\hline In-patient & 67 & 15.4 & 6 & 3.3 & 73 & 11.9 & & & \\
\hline Low secure unit & 16 & 3.7 & 7 & 3.8 & 23 & 3.7 & & & \\
\hline Medium secure unit & 0 & 0 & 1 & 0.5 & 1 & 0.2 & & & \\
\hline Other secure environment & 4 & 0.9 & 0 & 0 & 4 & 0.6 & & & \\
\hline Total & 434 & 100.0 & 182 & 100.0 & 616 & 100.0 & & & \\
\hline
\end{tabular}

\begin{tabular}{|c|c|c|c|c|c|c|c|c|c|}
\hline & \multicolumn{2}{|c|}{ Independent sector } & \multicolumn{2}{|c|}{ NHS } & \multicolumn{2}{|c|}{ Total } & \multirow{2}{*}{$\begin{array}{l}\text { Fisher's } \\
\text { exact test }\end{array}$} & \multirow[b]{2}{*}{$\chi^{2}$} & \multirow[b]{2}{*}{$P$} \\
\hline & $n$ & $\%$ & $n$ & $\%$ & $n$ & $\%$ & & & \\
\hline $\begin{array}{l}\text { Responsible clinician considers patient to be at } \\
\text { the right level of security on census date }\end{array}$ & & & & & & & & 0.491 & 0.484 \\
\hline Yes & 182 & 91.9 & 249 & 93.6 & 431 & 92.9 & & & \\
\hline No & 16 & 8.1 & 17 & 6.4 & 33 & 7.1 & & & \\
\hline Total & 198 & 100 & 266 & 100.0 & 464 & 100 & & & \\
\hline Recommended placement in 1 year & & & & & & & 53.915 & & $<0.001$ \\
\hline Community & 18 & 9.2 & 73 & 28.4 & 91 & 20.1 & & & \\
\hline In-patient & 11 & 5.6 & 24 & 9.3 & 35 & 7.7 & & & \\
\hline Low secure unit & 90 & 45.9 & 63 & 24.5 & 153 & 33.8 & & & \\
\hline Medium secure unit & 76 & 38.8 & 81 & 31.5 & 157 & 34.7 & & & \\
\hline Prison & 1 & 0.5 & 0 & 0 & 1 & 0.2 & & & \\
\hline Other secure environment & 0 & 0 & 16 & 6.3 & 16 & 3.5 & & & \\
\hline Total & 196 & 100 & 257 & 100 & 453 & 100 & & & \\
\hline Recommended placement in 4 years & & & & & & & 23.122 & & $<0.001$ \\
\hline Community & 118 & 61.5 & 182 & 74.9 & 300 & 69 & & & \\
\hline In-patient & 15 & 7.8 & 12 & 4.9 & 27 & 6.2 & & & \\
\hline Low secure unit & 42 & 21.9 & 32 & 13.2 & 74 & 17.0 & & & \\
\hline Medium secure unit & 14 & 7.3 & 7 & 2.9 & 21 & 4.8 & & & \\
\hline Prison & 0 & 0 & 2 & 0.8 & 2 & 0.5 & & & \\
\hline Other secure environment & 3 & 1.6 & 7 & 2.9 & 10 & 2.3 & & & \\
\hline Return to country of origin & 0 & 0 & 1 & 0.4 & 1 & 0.2 & & & \\
\hline Total & 192 & 100 & 243 & 100 & 435 & 100 & & & \\
\hline
\end{tabular}

striking and is consistent with the number of women with emotionally unstable personality disorder or intellectual disability. This should prompt an urgent debate parallel to that about managing challenging behaviour. ${ }^{11}$ It also invites discussion about the availability, configuration and commissioning of suitable, less secure alternatives that might be less stigmatising.

\section{Placement, sector and geography: many women far from home}

Our results suggest the NHS is catering to its local population. This is much less true of the independent sector where many women are far from home. Overall, a third of women are placed outside their region of origin, although it cannot be assumed this is always a long way away. Some diagnostic groups seem particularly at risk of out of region placement, at odds with a principle of equity of provision for those in need of secure care. ${ }^{12}$ This configuration of service provision has a greater impact on the women needing low secure care since the independent sector cares for most of them. It is apparent that women's rehabilitation in their own communities may be compromised. Women's quality of life in terms of contact with family, links with local services, discharge planning and resources required to monitor their progress are more difficult if geographical placements are distant. Distant placements of this kind are inefficient and at odds with past and present national guidance. ${ }^{13}$ 
Set against this is the unexpected finding that independent sector MSU placements are shorter than those in the NHS. Possible explanations are active case management by commissioners or simply that these women pose less risk and therefore can be moved on faster. Beds purchased on an individual basis, rather than a block contract basis, may be scrutinised more closely than those where the purchasing decision and financial outlay can only be influenced annually or perhaps every 3 years. Part of the explanation may be that women are returned from outlying independent sector units to local NHS care to facilitate community care planning in areas where they have established rights and ties. Such transfer of individuals between the same levels of security may be thought appropriate at the time but inevitably adds delay and complexity to the 'patient journey'.

\section{Decision-making and the complex patient journey}

This study demonstrates the complexity of routes for women into and out of secure psychiatric services and to and from different levels of security. The study findings characterise the populations of women in medium and low security, both in the NHS and independent sector, at only one point in a journey of care that can last years. The unplanned patterns of care described reveal the results of many small clinical, legal and commissioning decisions made in the previous absence of a national women's strategy. The data shed less light on the decision-making process (i.e. it tells us what has been done but not why or indeed who has done this). The escalating cost of secure hospital care demands that we also try to understand the processes to improve efficiency. ${ }^{4,14}$

Phillips \& Bane e Costa $^{15}$ are rare in providing a model of problems found in public sector decision-making. Their work identifies the following five factors, which, they argue, contribute to poor decision-making: multiple and conflicting objectives, insufficient detail to assess options, devolution of decision-making compromising overall quality of decision-making, too many people involved and perverse and disruptive personal investment in non-approved outcomes. Taking these in order, it is possible to explore the extent to which their model can explain the service patterns established above.

First, decisions to admit to hospital involve not just clinicians, but commissioners, operational managers and often the criminal justice system, both courts and prisons. ${ }^{16}$ As they suggest, multiple, shifting and potentially competing discourses, especially legal, public policy and clinical contributions on rights and risk, all inform clinical placement decisions; ${ }^{17,18}$ patient choice, which might favour proximity to home, is less relevant, ${ }^{19}$ in contrast to elsewhere. ${ }^{20}$

Second, specialist health commissioners determine which providers are acceptable, ${ }^{21,22}$ a refinement of early attempts to create internal markets, designed to reduce cost and enhance quality. ${ }^{2}$ Commissioning is intrinsically distant from both patient and provider service. Clinical detail is not their responsibility. The small numbers of female forensic patients that come their way are unfamiliar. The consequent lack of nuanced understanding of both their clinical issues and their services may adversely affect the quality of the decisions about individual and block clinical placements.

Third, the local nature of NHS commissioning, based either on regional specialist commissioning groups for traditional forensic services, or on primary care trusts for other secure bed purchase, has historically given limited access to national information (both clinical data-sets and comparative costs of services). Wilson et $\mathrm{al}^{14}$ also note the degree of separation of these commissioning systems; local primary care trusts are even less familiar with the clinical market as they buy few secure beds. This lack of national coordination must have an impact on commissioning efficacy for example to find urgent, empty beds or rare beds (such as for women with autism), or better value for money. Even the size of the secure hospital provider estate for women was unknown until recently. ${ }^{7}$ There has been no routine grasp of the occupancy rates reported here and no national structure to locate beds close to home for women or to cluster women with specialist needs. This tends to supports Phillips \& Bane e Costa's contention that the devolution of responsibility compromises decision-making quality. ${ }^{15}$

Fourth, the system involves not only multiple agencies but also a large number of individual professionals. The system of secure care has been described as 'sluggish. ${ }^{14}$ There is separate evidence of how it can serve women badly, for example slow secure hospital transfers from prison, ${ }^{23,24}$ but it is hard to see how this contributes to the patterns of placement reported here.

Fifth, this study has provided evidence that NHS and independent sector secure services serve distinct groups of women. Until April 2013, commissioning arrangements for these sectors have been substantially different. Legally, this has now changed and an increasing role for the independent sector providers, many of which are 'for profit' organisations, is anticipated (Health and Social Care Act 2012). ${ }^{8,20}$ This study would suggest that further growth in this sector of mainly private healthcare might exacerbate the independent sector's evident tendency to locate women out of area, in line with its acknowledged business model. At the same time, NHS providers have failed to address specialist needs locally. These are 'non-approved' outcomes but may be as much to do with organisational as personal investment.

Consideration of the five components of the Phillips \& Bane e Costa ${ }^{15}$ model suggests it is partially supported by the study data. To explore the issue more fully would require an additional approach to get below the surface of the organisations involved. Placement pattern obviously relates to woman-specific factors (as is clear from the study results) but also to wider organisational issues. Decisions might be said to lack the procedural transparency required for truly legitimate decision-making in the health arena. $^{25}$

These data have been obtained as a labour intensive one-off exercise; strikingly, no attempt has been made to examine the much larger national male forensic population. Commissioners and providers need to cooperate and use up-to-date technology, such as Google maps, to monitor service utilisation in a routine and transparent way without jeopardising patient confidentiality. Patterns of placement and durations of stay must be part of the ready arsenal of both providers and commissioners, not the preserve of one or the other. To be effective, such information needs to be current and both local and national.

It will be intriguing to witness the further evolution of secure women's services as NHS England takes up the reins of nationally benchmarked commissioning. It will be vital to monitor these services, and their capacity to deliver gender sensitive care, ${ }^{1}$ better than has been the case in the past.

\section{Limitations}

The study has a number of limitations. There is a lack of researchbased diagnosis and reliance on clinicians' judgement on placement need in terms of security. No structured security needs questionnaire, such as Security Needs Assessment Profile (SNAP), ${ }^{26}$ or formal risk assessment instrument, such as Historical, Clinical and Risk Management Scales (HCR-20), ${ }^{27}$ was used. The response rate is high but lower for the low secure population than the medium secure population. 
Annie Bartlett, MRCPsych, PhD, Nadia Somers, MSc, Matthew Fiander, PhD, Department of Population, Health Sciences and Education, St George's, University of London, London; Mari Anne Harty, FRCPsych, PhD, Shaftesbury Clinic, Springfield University Hospital, London, UK

Correspondence: Annie Bartlett, MRCPsych, PhD, Department of Population, Health Sciences and Education, St George's, University of London, Cranmer Terrace, London SW170RE. Email: abartlett@sgul.ac.uk

First received 23 Sep 2013, final revision 19 Mar 2014, accepted 2 May 2014

\section{References}

1 Department of Health. Women's Mental Health: Into the Mainstream. Strategic Development of Mental Health Care for Women. Department of Health, 2002.

2 Mynors-Wallis, L. Cooperation or competition? Proposed changes in healthcare provision in England. Psychiatric Bull 2011; 35: 441-3.

3 Mental Health Strategies. 2009/10 National Survey of Investment in Adult Mental Health Services. Report Prepared for Department of Health. Mental Health Strategies, 2010.

4 Department of Health. No Health without Mental Health: A CrossGovernment Mental Health Outcomes Strategy for People of all Ages Supporting Document - The Economic Case for Improving Efficiency and Quality in Mental Health. Department of Health, 2011 (https://www.gov.uk/ government/publications/the-economic-case-for-improving-efficiency-andquality-in-mental-health).

5 Tilt R, Perry B, Martin C. Report of the Review of Security at the High Secure Hospitals. Department of Health, 2000.

6 Department of Health. Best Practice Guidance Specification for Adult Medium-Secure Services. Health Offender Partnerships, 2007.

7 Harty M, Somers N, Bartlett A. Women's secure hospital services: national bed numbers and distribution. J Forens Psychiatry Psychol 2012; 23: 590-600.

8 Laing, W. Mental Health Hospitals and Community Health Services. UK Market Report. Laing and Buisson, 2013.

9 Coid J, Kahtan N, Gault S, Jarman B. Women admitted to secure forensic psychiatry services: I. Comparison of women and men. J Forens Psychiatry 2000; 1: 275-95.

10 Maden A, Skapinakis $P$, Lewis $G$, Scott F, Burnett R, Jamieson E. Gender differences in reoffending after discharge from medium-secure units. National cohort study in England and Wales. Br J Psychiatry 2006; 189: $168-172$

11 Department of Health. Transforming Care: A National Response to Winterbourne View Hospital. Department of Health Review: Final Report Department of Health, 2012 (https://www.gov.uk/government/publications/ winterbourne-view-hospital-department-of-health-review-and-response).
12 Dixon A, Le Grand J, Henderson J, Murray R, Poteliakhoff E. Is the British National Health Service equitable? The evidence on socioeconomic differences in utilization. J Health Serv Res Policy 2007; 12: 104-9.

13 Department of Health and Home Office. Review of Health and Social Services for Mentally Disordered Offenders and Others Requiring Similar Services (Reed Report). Final Summary Report. HMSO, 1992.

14 Wilson S, James D, Forrester A. The medium-secure project and crimina justice mental health. Lancet 2011; 378: 110-1.

15 Phillips L, Bane e Costa C. Transparent Prioritisation, Budgeting and Resource allocation with Multi-criteria Decision Analysis and Decision Conferencing Working Paper LSEOR05.75. Department of Operational Research London School of Economics and Political Science, 2005

16 Naylor C, Bell A. Mental Health and the Productivity Challenge: Improving Quality and Value for Money. King's Fund, 2010

17 Peay J, Eastman NLG. Law without Enforcement: Integrating Mental Health and Justice. Hart, 1999.

18 Bartlett A, Kesteven S. Organisational and conceptual frameworks and the mentally disordered offender. In Forensic Mental Health: Concepts, Systems and Practice (eds A Bartlett and G McGauley): 327-38. Oxford University Press, 2009

19 Mezey G, Hassell Y, Bartlett A. Safety of women in mixed sex and single-sex medium secure units. Br J Psychiatry 2005; 187: 579-82.

20 Ham C. Regulating the NHS market in England. BMJ 2013; 346: f1608.

21 Department of Health. World Class Commissioning. Department of Health, 2009. (www.Icr.nhs.uk/Library/worldclasscommissioninganintroduction.pdf)

22 National Mental Health Development Unit. Mental Health World Class Commissioning. A Quick Guide for Mental Health Professionals. Commissioning Support for London, 2009 (http://www.Iondonhp.nhs.uk/ wp-content/uploads/2011/03/World-Class-Commissioning-a-quick-guide-formental-health-professionals.pdf).

23 Home Office. The Corston Report: A Report by Baroness Jean Corston of a Review of Women with Particular Vulnerabilities in the Criminal Justice System. Home Office, 2007.

24 Bartlett A, Somers N, Reeves C, White S. Women prisoners: an analysis of the process of hospital transfers. J Forens Psychiatry Psychol 2012; 23: 538-53.

25 Greb S, Niebuhr D, Rothgang H, Wasem, J. Criteria and procedures for determining benefit packages in healthcare: a comparative perspective. Health Policy 2004; 73: 78-91.

26 Collins M, Davies S. The Security Needs Assessment Profile: a multidimensional approach to measuring security needs. Int $J$ Forens Ment Health 2005; 4: 39-52.

27 Webster CD, Douglas KS, Eaves D, Hart SD. The HCR-20: Assessing the Risk for Violence (Version 2). Mental Health, Law, and Policy Institute, Simon Fraser University, Psychiatric Services Commission of British Columbia, 1997. 